\title{
Global Phylogeography of Salmonid Ectoparasites of the Genus Gyrodactylus, with an Emphasis on the Origin of the Circumpolar Gyrodactylus salmonis (Platyhelminthes: Monogenea)
}

\author{
ERIC Leis, ${ }^{1,4}$ Tran Kim Chi, ${ }^{2}$ AND JAAKKo Lumme ${ }^{3}$ \\ ${ }^{1}$ U.S. Fish and Wildlife Service, La Crosse Fish Health Center-Midwest Fisheries Center, Onalaska, Wisconsin 54650, \\ U.S.A. (e-mail: Eric_Leis@fws.gov), \\ ${ }^{2}$ Research Institute for Aquaculture No. 1, Dinh Bang, Tu Son, Bac Ninh, Vietnam (e-mail: tkchi@ ria1.org), and \\ ${ }^{3}$ Department of Ecology and Genetics, University of Oulu, 90064 Oulu, Finland (e-mail: Jaakko.Lumme@oulu.fi)
}

ABSTRACT: The wageneri species group of Gyrodactylus contains the following molecularly confirmed salmonid parasites in Asia: Gyrodactylus taimeni Ergens, 1971, Gyrodactylus magnus Konovalov, 1967, Gyrodactylus brachymystacis Ergens, 1978, and Gyrodactylus derjavini Mikhailov, 1975; in Europe it contains the following: Gyrodactylus derjavinoides Malmberg, Collins, Cunningham, and Jalali, 2007, Gyrodactylus truttae Gläser, 1974, Gyrodactylus teuchis Lautraite, Blanc, Thiery, Daniel, and Vigneulle, 1999, Gyrodactylus lavareti Malmberg, 1956, Gyrodactylus salvelini Kuusela, Ziętara, and Lumme, 2008 (presented herein as a junior synonym of Gyrodactylus salmonis Yin and Sproston, 1948), and Gyrodactylus salaris Malmberg, 1957, with the lone confirmed North American exception being G. salmonis. The mitochondrial DNA $(\operatorname{cox} 1,1545 \mathrm{bp})$ of this group shows a star-like phylogenetic expansion that began $2.05 \pm 0.4$ million years ago (mya), estimated from the mean distance of the $\operatorname{cox} 1$ gene $\left(d_{\mathrm{MCL}}=0.267\right)$ using a tentative, potentially high-end, divergence rate of 0.13/Myr. European G. salaris on Thymallus thymallus and Asian G. magnus on Thymallus arcticus have been separated for $1.95 \mathrm{Myr}\left(d_{\mathrm{MCL}}=0.253\right)$. The nuclear ITS rDNA region $(1,245 \mathrm{bp})$ of $G$. salmonis was nearly uniform among North American populations of Oncorhynchus mykiss, Oncorhynchus clarkii, Oncorhynchus nerka, Salvelinus fontinalis, and Salmo salar (and non-native Salmo trutta) as well as on Salvelinus alpinus (under the synonym G. salvelini) from Lake Inari, Finland. Gyrodactylus salmonis is distal in a monophyletic subclade labeled by an apomorphic 56 bp insertion in the ITS1, shared by the European parasites G. lavareti (host: Coregonus lavaretus), Gyrodactylus pomeraniae Kuusela, Ziętara, and Lumme, 2008 (host: Rutilus rutilus), and Gyrodactylus bliccensis Gläser, 1974 (host: Alburnus alburnus). This subphylogeny suggests that a particular host switch from cyprinids to salmonids may have occurred less than 1.8 mya in the Old World $\left[d_{\mathrm{MCL}}=0.234\right.$ G. pomeraniae vs (G. salmonis, G. lavareti)] and possibly again among coregonine hosts and Salvelinus $1.2 \mathrm{mya}\left(d_{\mathrm{MCL}=}\right.$ 0.156). Although hypothetical, a transition from coregonines to charr (notably the widely distributed and adaptable Salvelinus alpinus) potentially could have occurred in a proglacial refugium leading to circumpolar distribution of G. salmonis and a secondary transition to other North American hosts. The maximum cox 1 genetic distance within G. salmonis on all hosts was $d_{\mathrm{MCL}}=0.032$, at the same level as in multihosted European $G$. salaris $\left(d_{\mathrm{MCL}}=0.032\right)$, suggesting circa $250,000 \mathrm{yr}$ of population expansion with these parasites since a temporal, coinciding bottleneck.

KEY WORDS: Gyrodactylus salmonis, circumpolar, Monogenea, North America, Finland

Monogenean fish parasites within the genus Gyrodactylus are generally inconspicuous. In evolutionary equilibrium, the host and parasite appear generally coadapted, typically not causing harm to the host fish, and while their presence at fish farms may garner attention, the clinical signs are often mild (Cone and Cusack, 1988; Rokicka et al., 2007). However, when a parasite species infects a suitable naïve host, there can be serious consequences, such as the infamous invasion of Gyrodactylus salaris Malmberg, 1957, of Baltic origin on wild Atlantic salmon (Salmo salar) populations in Norway (Johnsen and Jensen, 1991). In this case, 3 separate invasions were identified by mtDNA and traced to commercial activity

\footnotetext{
${ }^{4}$ Corresponding author.
}

(Hansen et al. 2003). Prompted by these incidents, G. salaris became the scientific flagship for the genus (e.g., Bakke et al., 2007; Lumme et al., 2015), and the associated pragmatic needs rejuvenated research within this group (e.g., Gilmore et al., 2010, 2012 in North America). Still, the invasions that occurred in Norway, as well as a single instance in the White Sea basin, are the only clinically recognized pathological outbreaks of these "Russian Dolls" (Bakke et al., 2007) among wild salmon populations.

The application of molecular methods advanced taxonomic research in regard to Gyrodactylus, with the first successful genetic markers being the $18 \mathrm{~S}$ and ITS (ITS1-5.8S-ITS2) region of the nuclear ribosomal RNA gene cassette (Cunningham et al. 1995; Cunningham 1997; Matějusová et al., 2001; Ziętara and Lumme 2002). Later the mitochondrial marker cox 1 
improved resolution within species (Meinilä et al., 2002; Hansen et al., 2003, 2007). The ITS region and $\operatorname{cox} 1$ gene segments represent the gold standard for clinical and taxonomic "barcoding" as well as phylogenetic reconstructions of the genus (Vanhove et al., 2013). The primers available for the ITS segment are rather universal and widely used, systematically connecting parasites on different continents, including diverse subgenera (Ziętara et al., 2012; Hansen et al., 2012; Reyda et al., 2019). The published primers for mitochondrial DNA (cox1) are more specific, developed for and targeting the species in subgenus $G y$ rodactylus (Limnonephrotus), and in particular, the wageneri species group (Malmberg, 1970). Although potentially coincidental, all Gyrodactylus species that infect salmonids, except Gyrodactylus colemanensis Mizelle and Kritsky, 1967 (You et al., 2011), belong to this group. This subgenus is primarily restricted to freshwaters of the Old World, with the only continental outliers confirmed through molecular methods being Gyrodactylus salmonis Yin and Sproston, 1948, on salmonids and Gyrodactylus crysoleucas Mizelle and Kritsky, 1967, from a commercially farmed cyprinid, Golden Shiner Notemigonus crysoleucas (Leis et al., 2016). Morphologically identified North American species Gyrodactylus nerkae Cone, Beverley-Burton, Wiles, and McDonald, 1983 (Cone et al., 1983) and Gyrodactylus lucii Kulakovskaya, 1952 (Cone and Dechtiar, 1986) have not yet received molecular confirmation regarding their placement within this clade.

The wageneri group has exceptional diversity of host species within the phylogenetic time scale, with infections occurring on at least 7 fish families, although the species and strains remain quite host specific within the ecological time scale (Ziętara and Lumme, 2002). Host specificity has been thoroughly evaluated in Norway among strains of G. salaris (including the synonym Gyrodactylus thymalli Žitňan, 1960) on grayling (Thymallus thymallus), Arctic charr (Salvelinus alpinus), rainbow trout (Oncorhynchus mykiss), and Atlantic salmon (S. salar). All shared nearly identical ITS region sequences ( 1 to 4 divergent nucleotides) and were accepted as belonging to the same Gyrodactylus species, most recently by Fromm et al. (2014), despite differences in mitochondrial haplotype and host affinity (Bakke et al., 2007; Hansen et al., 2007; Olstad et al., 2007).

Herein, we focus on G. salmonis, which has been observed on several North American salmonid species within the genera Oncorhynchus, Salvelinus, and Salmo and frequently identified from aquaculture en- vironments (Cusack and Cone 1986; Cone and Cusack 1988). The first molecular identification of this species by Gilmore et al. (2010) showed that G. salmonis and Gyrodactylus salvelini Kuusela, Ziętara \& Lumme, 2008, described from Lake Inari in Finland on Salvelinus alpinus (Kuusela et al., 2008), shared identical ITS as well as levels of mitochondrial DNA variation typically observed within a species. This situation appeared corollary to that of the aforementioned G. salaris (synonym: G. thymalli).

In this study, we show that $G$. salvelini is a junior synonym of G. salmonis, and then we describe the phylogeographic framework for this parasite through analysis of new ITS and mitochondrial DNA data. Specimens were collected from 8 rainbow trout hatcheries in 3 states in the United States, complementing earlier observations in Canada (Gilmore et al., 2010, 2012) and Mexico (Rubio-Godoy et al., 2012). Data were also collected from 2 additional salmonid infecting Gyrodactylus spp. from eastern Asia. This geographic range expansion increases our understanding of the evolution within host-parasite communities while emphasizing the Holarctic circumpolar faunal divisions and connections. Additionally, a recent global evolutionary presentation of the genus Salvelinus (Esin and Markevich, 2018) offers a comprehensive framework for further research on G. salmonis as well as other salmonid parasites and their hosts in the phylogeographic theater of the Holarctic.

\section{MATERIALS AND METHODS}

Samples of G. salmonis, preserved in $70 \%$ ethanol, were obtained in 2011 from 8 rainbow trout farms in the United States, 5 in Washington (Eells Springs SFH [State Fish Hatchery]), Naselle SFH, Spokane SFH, Ford SFH, and a private farm on the Olympic Peninsula), 2 in Montana (Giant Springs SFH, Big Springs $\mathrm{SFH}$ ), and 1 in Pennsylvania (Lamar Fish Technology Center; USFWS). All samples were collected from subclinical infections. We also used sequences presented in previously published studies from Europe by Kuusela et al. (2008), the United States, and Canada by Gilmore et al. $(2010,2012)$, as well as Mexico by Rubio-Godoy et al. (2012). Samples of Gyrodactylus magnus Konovalov, 1967 (3 specimens) and Gyrodactylus taimeni Ergens, 1971 (7 specimens) were obtained from an O. mykiss farm in Bàn Khoang village, Sapa District, Lào Cai Province, northern Vietnam. Two specimens of G. magnus from Vladivostok, Russia, were also sequenced (courtesy of A. Ermolenko and M. Ziętara). 


\section{Morphological analysis}

Gyrodactylus, preserved in $70 \%$ ethanol, from Naselle SFH were briefly rehydrated in tap water, stained in Gomori's trichrome, cleared in clove oil, and mounted in Canada balsam. Morphometric evaluation was completed following Malmberg (1970). Voucher slides were submitted to the Smithsonian National Museum of Natural History (Washington, D.C.) under Accessions USNM 1655828-1655834. Photographs and measurements of G. salmonis (fixed in formalin and mounted in glycerin jelly) collected from cutthroat trout Oncorhynchus clarkii from the Nanaimo River Hatchery in 1981 were used for morphological comparison (courtesy of Dr. David Cone). Photographs of type specimens for $G$. salvelini were also examined. Measurements are reported in $\mu \mathrm{m}$.

\section{DNA extraction}

Parasite DNA was extracted by digesting individual specimens in $10 \mu \mathrm{l}$ of lysis solution with a final concentration as follows: $1 \times$ PCR buffer, $0.45 \%(\mathrm{v} / \mathrm{v})$ Tween $20,0.45 \%$ (v/v) NP 40, and $60 \mu \mathrm{g} / \mathrm{ml}$ proteinase $\mathrm{K}$ (Lumme et al., 2017). The tubes were incubated at $65^{\circ} \mathrm{C}$ for $25 \mathrm{~min}$ to allow for proteinase $\mathrm{K}$ digestion, followed by $95^{\circ} \mathrm{C}$ for $10 \mathrm{~min}$ to denature the proteinase and then cooled to $4^{\circ} \mathrm{C}$.

\section{PCR amplification of the ITS region and direct sequencing}

The entire ITS region of the ribosomal DNA array (spanning ITS1-5.8S-ITS2 and flanked by fragments of 18 S and 28S) was amplified with ITSIF (5'GTTTC CGTAG GTGAA CCT) (Ziętara et al., 2000; Rokicka et al., 2007) and ITS2R (5'-GGTAA TCACG CTTGA ATC) primers (Ziętara et al., 2000; Ziętara and Lumme, 2002). The PCR reaction contained $2 \mu 1$ of lysate, $1 \times$ PCR buffer, $2 \mathrm{mM} \mathrm{MgCl}_{2}, 1 \mu \mathrm{M}$ of each primer, $200 \mu \mathrm{M}$ of each dNTP, and 0.4 units of Taq polymerase (Fermentas) in final volume of $20 \mu \mathrm{l}$. Thermocycler parameters were as follows: $3 \mathrm{~min}$ at $95^{\circ} \mathrm{C}$, 37 cycles of $94^{\circ} \mathrm{C}, 48^{\circ} \mathrm{C}$, and $72^{\circ} \mathrm{C}$ for $1 \mathrm{~min}$ each, followed by $7 \mathrm{~min}$ at $72^{\circ} \mathrm{C}$ and concluding with cooling to $4^{\circ} \mathrm{C}$. The amplified fragments were purified from the agarose gel using ExoSAP following the manufacturer's procedure and sequenced directly with ITSIF and $I T S 2 R$ as well as with 2 internal primers in $5.8 \mathrm{~S}$ region, ITS1R (5'-ATTTG CGTTC GAGAG ACCG) and ITS2F (5'-TGGTG GATCA CTCGG CTCA), as described earlier (Ziętara and Lumme, 2003, 2004; Ziętara et al., 2008)

\section{Amplification and sequencing of mitochondrial DNA}

The analysis of mitochondrial DNA was conducted as previously described (Meinilä et al., 2002; Ziętara et al., 2006). The $20 \mu \mathrm{l}$ PCR reaction consisted of $1 \times$ PCR buffer, $0.2 \mathrm{mM}$ dNTPs, $2 \mathrm{mM} \mathrm{MgCl}_{2}, 1 \mu \mathrm{M}$ of each primer, $0.5 \mathrm{U}$ of Fermentas Taq DNA polymerase, and $2 \mu \mathrm{l}$ of extracted DNA. The cox 1 gene was amplified either as a single fragment or as 2 overlapping fragments with $\operatorname{Tr} p 2 F$ 5'-TTTTA GACGA TTTGT TTTCA and Thr2R 5'-ATAGA TTGCT TGGTA TTACA primers. The $3^{\prime}$ end was amplified with $F \operatorname{Cox} 75^{\prime}$-TTTTC AATAG GTATG GACGT and $T h r 2 R$. Thermocycler parameters were as follows: $94^{\circ} \mathrm{C}$ for $3 \mathrm{~min}, 38$ cycles of $94^{\circ} \mathrm{C}$ for $30 \mathrm{sec}, 48^{\circ} \mathrm{C}$ for $1 \mathrm{~min}$, and $72^{\circ} \mathrm{C}$ for $1 \mathrm{~min} 50 \mathrm{sec}$, followed by $72^{\circ} \mathrm{C}$ for $7 \mathrm{~min}$, and a final cooling to $4^{\circ} \mathrm{C}$.

\section{Data analysis}

The phylogenetic hypotheses presented for the ITS region were constructed using Kimura's 2 parameter distance (K2P) and analysis of the Maximum Composite Likelihood distance $\left(d_{\mathrm{MCL}}\right)$ for the mitochondrial gene was completed with the MEGA7 program package (Kumar et al., 2016). Final checking and additional data handling were completed in MEGA X (Kumar et al., 2018). Phylogenetic trees were constructed with the Neighbor Joining or Maximum Likelihood methods. The optimal model for distance estimates and mitochondrial phylogenetic trees was GTR $+\mathrm{G}+\mathrm{I}$, with shape parameter $\alpha=1.28$. The trees produced were quite robust as all alternative methods and options produced the same topology along with similar bootstrap values.

In order to transform the mitochondrial genetic distance estimates $\left(d_{\mathrm{MCL}}\right)$ to reflect more illustrative geological times, we used the value of 0.13 divergence per million years, which was calculated for $G$. salaris (Kuusela et al., 2007) and recalibrated through the stickleback parasite G. arcuatus from the previously glaciated region of northern Europe (Lumme, Mäkinen, et al., 2016). The value 0.13 may represent the upper end of the divergence values and could be replaced if reliable calibration points can be presented in the future.

The sequences produced in this study were deposited in GenBank with accession numbers (MN854069-78 for the cox1 gene; MN850538-48 for the ITS region). Previously published sequences included in the phylogenetic analyses were from 
Kuusela et al. (2007) (G. salaris, including the synonym G. thymalli), Kuusela et al. (2008) (G. salmonis clade, including the synonym $G$. salvelini), Ziętara et al. (2010) (G. lucii, G. salaris "alien" cox1), Hahn et al. (2015) (Gyrodactylus teuchis Lautraite, Blanc, Thiery, Daniel, and Vigneulle, 1999, and Gyrodactylus truttae Gläser, 1974), Ieshko et al. (2015) (G. teuchis), and Lumme, Anttila, et al. (2016) (G. salaris). The phylogenetic reconstructions were generally based on complete 1,545 bp sequences of the cox 1 gene, although some shorter sequences (e.g., G. teuchis [1,355 bp] and G. truttae [1,349 bp]; Hahn et al., 2015) were included using pairwise deletion options.

\section{RESULTS}

\section{Gyrodactylus salvelini is a junior synonym of Gyrodactylus salmonis}

Measurements, reported in $\mu \mathrm{m}$ as a range, were obtained from 7 specimens from Naselle SFH. The parasites were identified as G. salmonis, sharing consistent morphology and characteristics with the report by Mueller (1936), although slightly larger than measurements reported by Cone et al. (1983). Anchors were 62-70 long, point 32-34, and shaft 52-59. Marginal hooks were $40-48$ in total length, with a sickle 7-9 long. Ventral bar featured minute bump-like anterolateral processes, $25-26$ in transverse width and 6-8 in medial length, and a total length (including the posterior membrane) of 21-25. Overall the morphology and measurements were very similar to G. salmonis collected from $O$. clarkii at the Nanaimo River Hatchery: anchors (61-69 long, 31-37 point, shaft 48-55), marginal hook (45-48 total length, 8-9 sickle length), and ventral bar (25 in transverse width; 9-12 in medial length; 18-28 in total length). The most significant morphological finding was that the size and shape of the taxonomically important marginal hook sickle were essentially identical among the specimens of $G$. salmonis identified during this study, those collected from $O$. clarkii during the redescription by Cone et al. (1983), as well as those from the description of G. salvelini. While the anchors of North American specimens $(66 \mu \mathrm{m})$ were smaller than those described for G. salvelini ( $87 \mu \mathrm{m}$; Kuusela et al. 2008), considerable seasonal variation in anchor size, apparently influenced by water temperature, has been noted with other Gyrodactylus species (Mo et al. 1991, 1993; Ondračková et al. 2020).

Molecular analysis revealed that the ITS sequence data was nearly identical (99.84-100\% similarity) among all specimens, including $G$. salvelini, which was identical to G. salmonis sequenced from Montana, Pennsylvania, and Washington. The variation of the $\operatorname{cox} 1$ gene $\left(d_{\mathrm{MCL}}=0.032\right)$ for all specimens, including $G$. salvelini, was within a range typically observed for a species sampled across geographical regions. We conclude that $G$. salvelini Kuusela, Ziętara \& Lumme, 2008, is a junior synonym of G. salmonis Yin and Sproston, 1948. The GenBank accessions of the ITS and cox 1 submitted as G. salvelini have been changed by the authors to G. salmonis (EF113106, EF524572). This conclusion allows us to present $G$. salmonis as the first molecularly confirmed circumpolar species of freshwater Gyrodactylus.

\section{ITS2 phylogeny}

A phylogenetic hypothesis based on the nuclear ITS2 fragment for species in the wageneri group, including Gyrodactylus crysoleucas, the only other North American species confirmed to be in the wageneri group, is presented in Figure 1. A noteworthy observation from this phylogeny is that the salmonid parasites do not form a common clade but appear scattered despite their substantial representation in the database. The basal portion of the phylogenetic hypothesis in Figure 1 is rather unresolved, indicating rapid splitting and allopatric isolation into independently developing lineages. The separate clade of $G$. pomeraniae, G. lavareti, and G. salmonis is moderately supported in Figure 1 (74\%) and featured a systematically informative insertion in the ITS region that deserved further analysis.

\section{The nuclear ITS region shows the origin of G. salmonis}

A phylogenetic hypothesis displaying the origin of G. salmonis is presented based on the sequenced regions of the ITS1-5.8S-ITS2 ( 1,250 bp; Fig. 2). In the phylogeny leading to G. salmonis, there is a unique, apomorphic 56 bp insertion observed within the hypervariable segment of the ITS1 (also see Kuusela et al., 2008). This insertion was identified in G. salmonis (all hosts), G. lavareti Malmberg, 1956 (host: Coregonus lavaretus; several localities in Finland), Gyrodactylus pomeraniae Kuusela, Ziętara, and Lumme, 2008 (host: Rutilus rutilus; Poland and Belgium), and Gyrodactylus bliccensis Gläser, 1974 (host: Alburnus alburnus; Czech Republic, River Morava; Matějusová et al., 2001) and in the hybrid of G. pomeraniae $\times$ Gyrodactylus lavareti (host: O. mykiss, Finland and Russian Karelia). The cyprinid parasite Gyrodactylus 


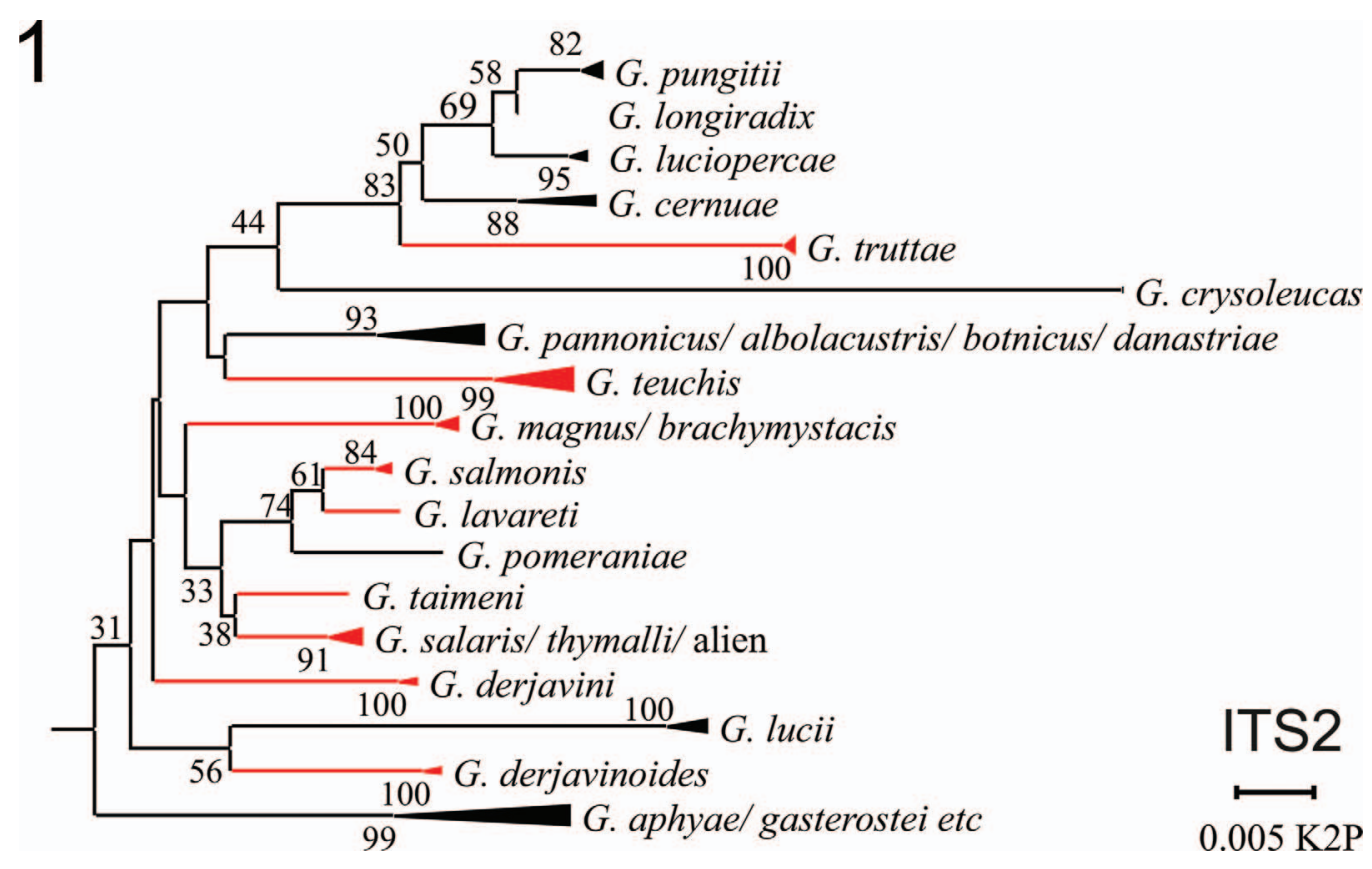

Figure 1. A phylogenetic hypothesis of the ITS2 region for Gyrodactylus species within the wageneri group, including all known to infect salmonids from Europe, Asia, and North America (marked red). The tree is rooted with non-wageneri members of subgenus G. (Limnonephrotus). Note that the North American Gyrodactylus crysoleucas is included. Neighbor Joining, K2P distances.

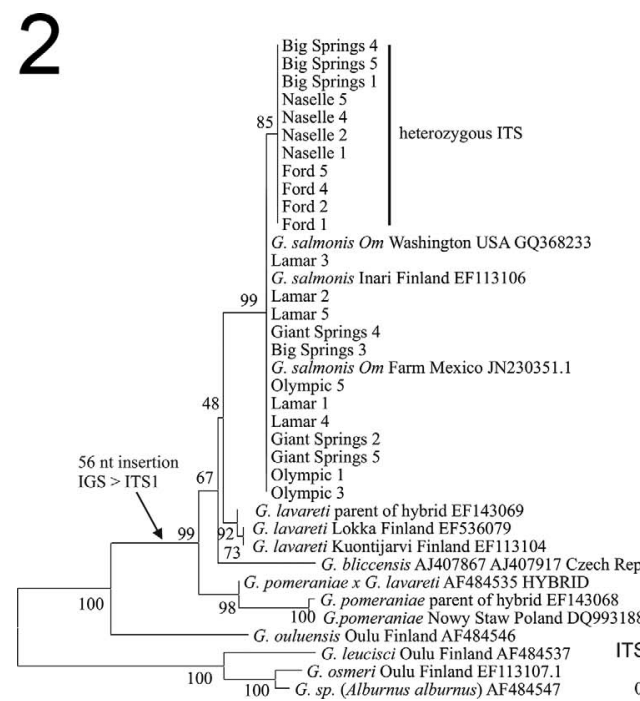

ITS1-5.8S-ITS2 $0.0050 \mathrm{~K} 2 \mathrm{P}$
G salmonis JN230352 O. mykiss Mexico 95. Big Springs 5 ${ }_{74}$ Naselle

- Giant Springs 5

7. Giant Springs 2

- Giant Springs 4

G. salmonis GQ368228 O. clarkii Agassiz BC

65. G salmonis $\mathrm{GQ368224}$ O. mykiss

. Ford $1 \longrightarrow$ heterozygous ITS

- Big Springs 3

. Big Springs 4

- Lamar 1

73 - Lamar 2

. Lamar 3

. Lamar 4

. Lamar 5

- Olympic 1

9 -Olympic 3

$G$ salmonis $\mathrm{GQ} 362222$ S. salar $G$ salmonis GQ368223 S fontinalis G. salmonis EF524572 S alpinus Inar G. lavareti Kuontijarvi Finland EF446762 G. lavareti Kuontijarvi EF 446763 G. lavareti Kuontijarvi EF446764

99. G. lavareti Lokka Finland EF524571 G.pomeraniae parent of hybrid AY225306 G. pomeraniae Novy Staw Poland EF446766 G. pomeraniae Vaart Belgium EF693955

Mitochondrial cox1

$\overline{0.020 \mathrm{MCL}}$

Figure 2. Left: Phylogenetic hypothesis of Gyrodactylus salmonis and the nearest relatives based on alignments of the long ITS1-5.8S-ITS2 sequence. The scale bar represents the number of base substitutions per site (K2P). Right: Mitochondrial Maximum Likelihood tree of the subclade that contains the $56 \mathrm{bp}$ insertion in the ITS1 G. salmonis. 


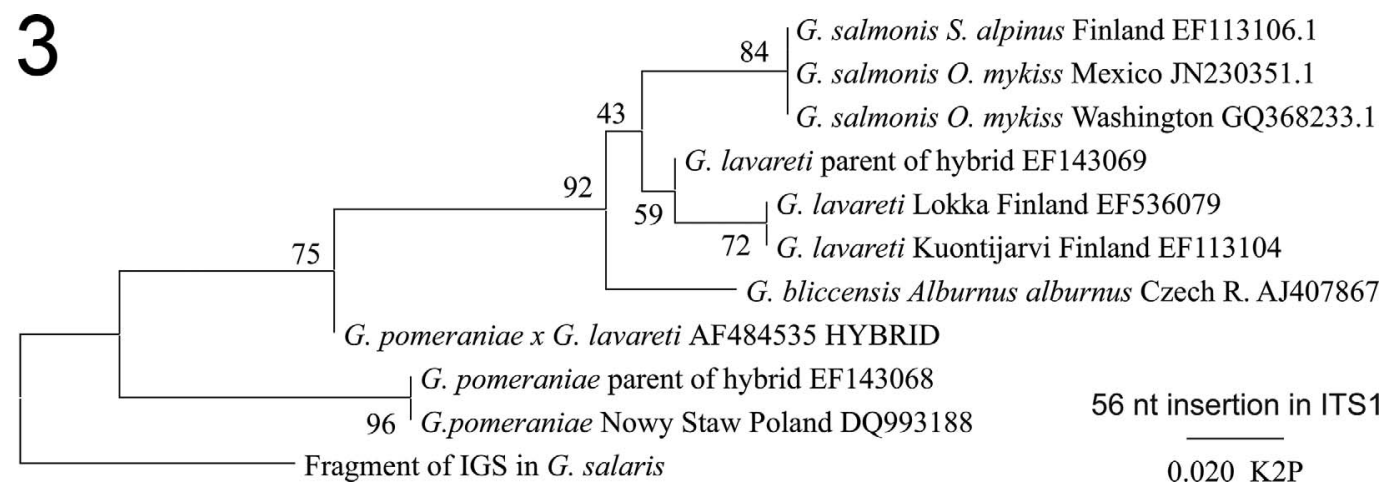

Figure 3. A phylogenetic hypothesis showing the clade-specific evolution of the 56 bp insertion in the ITS 1 region.

ouluensis Kuusela, Ziętara, and Lumme, 2008 (host: $R$. rutilus) belongs to the same clade but was basally located and, interestingly, lacked this $56 \mathrm{bp}$ insertion. The ITS tree was rooted with a sister outgroup consisting of the following: Gyrodactylus leucisci Žitñan, 1964 (host: Leuciscus idus), an undescribed Gyrodactylus sp. (host: $R$. rutilus), and Gyrodactylus osmeri Rumyantsev, Shul'man et Ieshko, 1998 (host: Osmerus eperlanus).

The 56 bp insertion in the hypervariable segment of the ITS1 apparently originated from the Intergenic Spacer (IGS) segment of the ribosomal DNA cassette, a sequence that has previously been identified from $G$. salaris (see Kuusela et al., 2008). The fragment was localized in the nonrepeated segment, position 889948, in the $2.62 \mathrm{~kb}$ PCR product of the IGS (GenBank AJ276032; Collins and Cunningham 2000). The phylogenetic evolution of the $56 \mathrm{bp}$ fragment is illustrated in Figure 3.

The genotype among all isolates of G. salmonis, including the Finnish sample, was generally uniform. There were also a few shorter published ITS sequences from G. salmonis on Salvelinus fontinalis (Nova Scotia), Salmo salar (Maine), O. mykiss (Washington, British Columbia), and O. clarkii (British Columbia; Gilmore et al., 2010), as well as on Onchorhynchus nerka (British Columbia; Gilmore et al., 2012), which were identical with the standard $\mathrm{C}^{16} \mathrm{~A}^{898}$. A heterozygous variant $\mathrm{M}^{16} \mathrm{~W}^{898}$ of the ITS region, differing by 2 transversions, was observed in 3 rainbow trout farms in the North American samples (Big Springs SFH in Montana and Naselle SFH and Ford SFH in Washington). The heterozygous clone in 3 separate North American facilities appears to be a cross between the standard G. salmonis and a derived strain $\mathrm{A}^{16} \mathrm{~T}^{898}$, which did not appear in our study. Site 898 was re- ported as either T or A in the 13 sequences from Mexico, but site 16 on the $5^{\prime}$ end was missing from these 1,168 bp-long samples (Rubio-Godoy et al., 2012). In our material, the $\mathrm{M}^{16} \mathrm{~W}^{898}$ heterozygote was combined with more than 1 mitochondrial haplotype (Fig. 2 ), suggesting this was not a single clone but was produced through repeated hybridizations.

\section{Mitochondrial phylogeny of salmonid parasites in the wageneri group}

We used a mitochondrial phylogenetic hypothesis of 16 named species within the wageneri group for rooting and scaling the phylogenetic clade containing G. salmonis (Fig. 4). The key finding, observed in both nuclear and mitochondrial DNA analyses, was the lack of a salmonid specific clade. A moderately supported but early diverged clade (77\% bootstrap support in $\mathrm{NJ}$, only $54 \%$ in ML tree) included the mitochondrial lineages of G. magnus and G. salaris. The type host of G. magnus is Arctic grayling (Thymallus arcticus) in eastern Russia; it was also found in an O. mykiss farm in Vietnam and sequenced on Manchurian trout Brachymystax lenok as Gyrodactylus brachymystacis Ergens, 1978, by Gilmore et al. (2010). The G. magnus clade differs from G. salaris by $d_{\mathrm{MCL}}=0.253$, with both lineages infecting Thymallus spp. on opposite regions of the continent suggesting almost $2 \mathrm{Myr}$ of allopatric separation. The allopatric variation of G. salaris on European grayling (T. thymallus) suggested grayling was the original host of G. salaris, which then transferred to $S$. salar via hybridization $a f$ ter the Eemian interglacial period 130 thousand years ago (kya) in the primordial refugium maintaining the later-evolving Baltic salmon stocks (Kuusela et al., 2008). The maximum divergence measured within the 


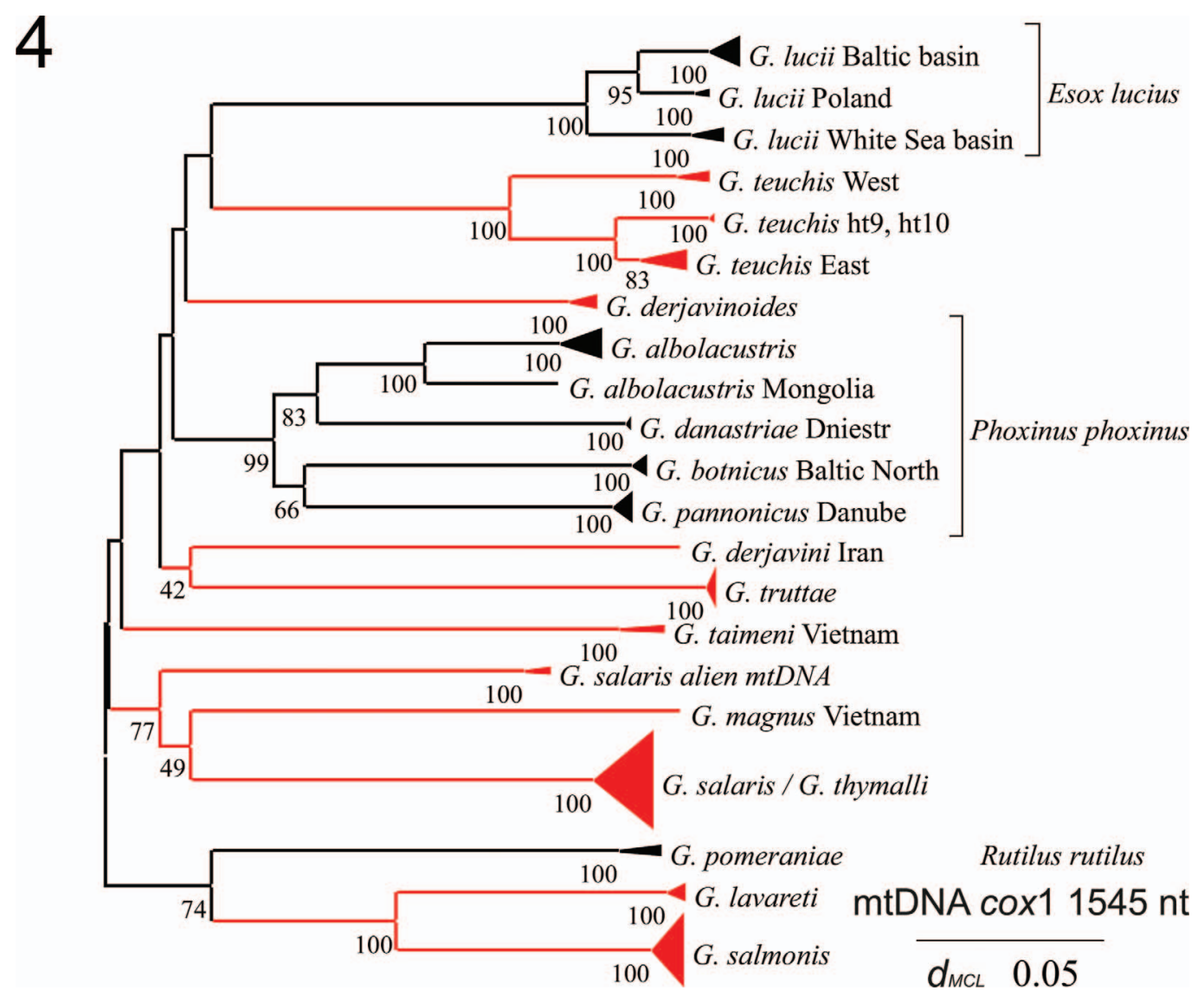

Figure 4. A mitochondrial phylogenetic hypothesis of selected species of Gyrodactylus within the wageneri species group. Salmonid parasites shown in red. Gyrodactylus lucii on Northern Pike (Esox lucius) and 4 allopatric species on Eurasian Minnow (Phoxinus phoxinus) were included for scaling, displaying the early divergence of the salmonid parasites. The Neighbor Joining tree was based on maximum composite likelihood distances $\left(d_{\mathrm{MCL}}\right)$ of 135 complete cox 1 sequences $(1,545 \mathrm{bp})$. The rate variation among sites was modeled with GTR model with gamma distribution (shape parameter 1.28).

Baltic salmon specific clade of $G$. salaris was $d_{\mathrm{MCL}}=$ 0.011 (85 kya).

\section{DISCUSSION}

\section{The taxonomic history of Gyrodactylus salmonis}

Gyrodactylus salmonis was originally described as "Gyrodactylus elegans, variety B" from various trout species examined from Ithaca, New York, U.S.A., as well as the state of Washington, mentioning that forms of the parasite collected from cutthroat trout, brown trout, brook trout, and rainbow trout all shared "uniform characters" (Mueller, 1936). Then Yin and Sproston (1948), with whom the taxonomic authority rests, mentioned measurement data from Mueller (1936) for G. elegans but also included the subspecies salmo- nis from "various trout in the U.S.A." The most thorough description was completed by Cone et al. (1983), where this parasite was redescribed as $G$. salmonis Yin and Sproston, 1948, using specimens collected from hatchery raised cutthroat trout. Unfortunately, the Nanaimo River Fish Hatchery, where Cone et al. (1983) redescribed G. salmonis, no longer produces cutthroat trout that could have potentially hosted $G$. salmonis for comparison. In this study, we collected specimens identified as $G$. salmonis from rainbow trout from the state of Washington, both of which were mentioned by Mueller (1936), to compare with G. salvelini.

Gilmore et al. (2010) mentioned differences in anchor size regarding why they did not synonymize G. salmonis and G. salvelini. However, several studies have shown that variation in anchor size for 
Gyrodactylus spp. can occur seasonally and be quite substantial (Mo, 1991, 1993; Ondračková et al. 2020), with differences up to $\sim 20 \mu \mathrm{m}$ in the case of G. salaris (Mo, 1991). Furthermore, Ondračková et al. (2020) found significant differences among the anchor sizes of Gyrodactylus specimens from different continents. While synonymization based on morphology alone would not be convincing in this case, with the only impediment being incongruent anchor sizes, the molecular data clearly connect $G$. salmonis and G. salvelini. The ITS data were identical among G. salvelini and several North American G. salmonis specimens. The ITS region is the most widely used sequence in $G y$ rodactylus taxonomy because of its high level of variability even among closely related species. The authors are unaware of any phylogenetic analysis where $2 \mathrm{~Gy}$ rodactylus samples shared identical ITS1/5.8S/ITS2 sequences and were still considered separate species. Additionally, the similarity of the mitochondrial sequences was consistent with a single species sampled across a geographic region, further supporting the conspecific nature of $G$. salmonis and G. salvelini. It is important to note that molecular data for G. salmonis were unavailable when $G$. salvelini was described, making it difficult to conceive that the parasite could have been found on continents separated by a marine environment. If the molecular data had been available at that time, the species would have been identified as $G$. salmonis. We conclude, based on morphological and genetic data, that $G$. salvelini is a junior synonym of $G$. salmonis.

\section{Mitochondrial phylogeny of salmonid parasites in the wageneri group}

The global phylogenetic hypothesis of selected $w a-$ generi group species (Fig. 5) separated most salmonid parasites as ancient lineages with very long "barcoding gaps," extending well beyond the $4 \times$ rule to separate species (Birky and Barraclough, 2009). The cox 1 tree suggested a star-like expansion (Fig. 5) from the Most Recent Common Ancestor (MRCA) for the $w a-$ generi group with a nearly simultaneous separation of numerous lineages 1.64 to 2.48 million years ago (mya; $d_{\mathrm{MCL}}=0.213$ to 0.322 ) leading to the extant species presently observed. The mean genetic distance between the distal OTUs was $d_{\mathrm{MCL}}=0.267$, suggesting the timing of the MRCA as 2.05 mya.

The range of the mitochondrial variation within $G$. salmonis on all hosts (Fig. 4; $\max d_{\mathrm{MCL}}=0.032$ ) represents the latest wave of expansion since a possible glacial bottleneck. It is similar to the variation of $G$. salaris on European hosts, including the original hosts S. salar, Salmo letnica, and T. thymallus, as well as the imported $O$. mykiss and S. fontinalis ( $\max d_{\mathrm{MCL}}=$ 0.032). The circumpolar Gyrodactylus arcuatus Bychowsky, 1933, on Gasterosteus aculeatus displays a similar level of mitochondrial variation $\left(\max d_{\mathrm{MCL}}=\right.$ 0.040; Lumme, Mäkinen, et al., 2016). The variation observed with $G$. arcuatus apparently originated on the Atlantic side of the globe because only a single strayed haplotype of the Barents Sea cluster was found in samples collected in the Pacific, from Vladivostok, Russia, as well as Puget Sound, Washington, U.S.A. (Lumme Mäkinen, et al., 2016). It is important to note that $G$. arcuatus is not a wageneri group species and is capable of spreading in marine environments, although the latest expansion with this species almost certainly occurred within continental, freshwater refugia.

The amount of interspecific variation in Asian G. taimeni (native hosts: Hucho taimen, B. lenok), Asian G. magnus (hosts: T. arcticus, Brachymystax lenok), Caspian Gyrodactylus derjavini Mikhailov, 1975 (host: Salmo trutta caspius), and European Gyrodactylus derjavinoides Malmberg, Collins, Cunningham, and Jalali, 2007 (host: S. trutta) is unknown, because these species have not been extensively sampled in their native range. The parasite strains "adopted" by the globally trafficked $O$. mykiss may be single, widely spread clones, thereby producing a deflated impression of the variation among the parasite species in the wild as some of these farm strains have not been observed in wild populations. Conversely, the variation among the 4 cox 1 haplotypes in $G$. salmonis from $O$. mykiss farms in the United States suggests these infections were not spread from 1 source, but the parasite was introduced to farms during several independent events, probably with several fish provenances. In Europe, the almost invariable $G$. truttae was analyzed on many $S$. trutta populations, suggesting complete geographical sampling coverage. However, the effects of modern human-facilitated dispersion are difficult to exclude, even when sampling among wild populations (Hahn et al., 2015).

\section{The wageneri species group of parasites is freshwater bound}

The distribution of G. salmonis is circumpolar and connected with species of Salvelinus and Oncorhynchus, which both have anadromous and landlocked forms. The continuous distribution of $S$. alpinus from Scandinavia to the Bering Strait and North America suggests a continuous distribution 


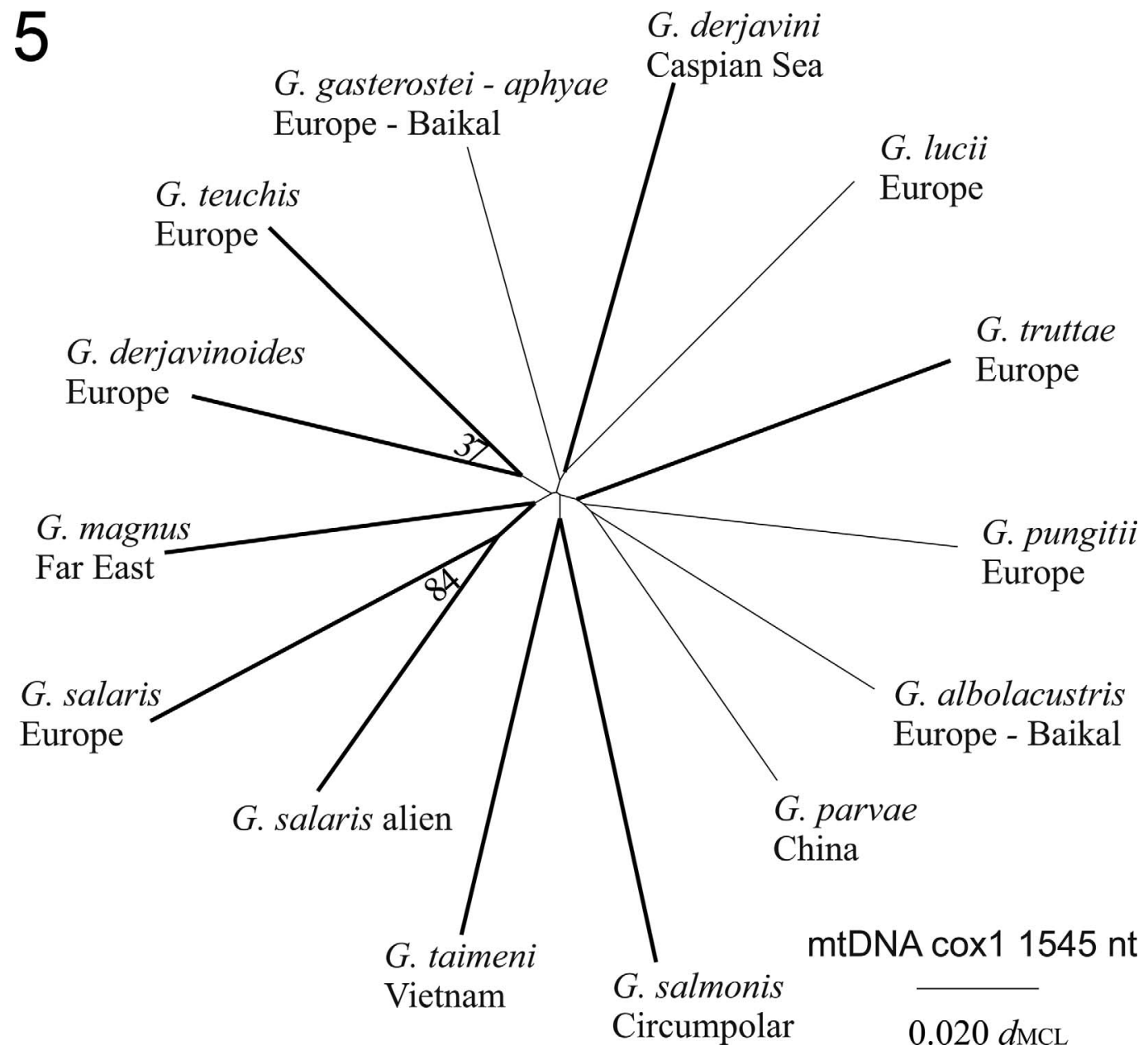

Figure 5. A radial tree based on the mitochondrial cox 1 gene of selected distal (extant) taxonomic units within the wageneri group. The data were reduced from Figure 4 for clarity and supplemented with a few unpublished taxa. Mean distance between the distal tips $d_{\mathrm{MCL}}=0.267$.

of $G$. salmonis as well, but due to freshwater dependency of the wageneri species group, we predict the parasite to be found exclusively in freshwaters (e.g., Lake Inari) and likely on the numerous Siberian relict isolates of Salvelinus (e.g., Salvelinus boganidae Berg, 1926, Salvelinus czerskii Drajagin, 1932, Salvelinus drjagini Logasschev, 1940, Salvelinus jacuticus Borisov, 1932, Salvelinus lepechini (Gmelin 1788), Salvelinus taimyricus Michin, 1949. Salvelinus taranetzi Kaganowsky, 1955, Salvelinus tolmachoffi Berg, 1926, and Salvelinus elgyticus Viktorovsky et Glubokovsky, 1981; all described as separate species in the Atlas of Russian Freshwater Fishes by Reshetnikov, 2003). These Russian charr species are likely periglacial relicts dispersed along the continuous freshwater habitats associated with the continental ice during the last glacial period. A recent comprehensive review suggested that dispersion of S. alpinus from a Siberian refugium both westwards and eastwards may have left behind the numerous isolates (Esin and Markevich, 2018). This may also be the case regarding the origin and spread of $G$. salmonis. The periglacial lake system in North America has been well illustrated by Power (2002), and the ice age lakes in northeastern Europe and Asia have been described by Mangerud et al. (2002), among others. Despite the scientific interest in charr evolution (Magnan et al., 2002), very little is known about the "parasite-supported phylogeography" of the genus. Parasite sampling among the salmonid populations of 
Coregonus, Thymallus, Oncorhynchus, and Salvelinus isolated along the northern edge of the Eurasian and North American continents would have the potential to be especially productive, likely shedding light on the general processes of biogeography. Additionally, the recent observation of Gyrodactylus birmani Konavolov, 1967, and Gyrodactylus sp. on Salvelinus albus and Salvelinus schmidti in Kronotsky Lake, Kamchatka Peninsula (Sokolov and Gordeev, 2014) are quite interesting and warrant molecular confirmation.

Herein, we suggest the wide distribution and limited variation of G. salmonis is connected with a relatively late transition to $S$. alpinus, possibly in a continental European refugium where paleolithic fossils of both Coregonus and Salvelinus, in addition to Thymallus, Salmo, Esox, and Cottus, have been found in sediments produced during the Last Glacial Maximum (Lõugas et al., 2013), followed by a subsequent spread along the northern continental margin of freshwater habitat associated with the genus Salvelinus (see Esin and Markevich, 2018). The pattern observed in the parasites on grayling, G. salaris (synonym: G. thymalli), on T. thymallus in Europe and G. magnus (possibly synonymous with $G$. brachymystacis) on $T$. arcticus in eastern Asia is similar. However, the allopatric clades apparently separated much earlier $\left(d_{\mathrm{MCL}}=0.253\right)$ and were not mixed during the continent-wide perturbation of the host genus observed in the Lake Baikal area (Koskinen et al., 2002).

Other freshwater species of Gyrodactylus with the potential to have a circumpolar distribution, although awaiting molecular confirmation, include Gyrodactylus lotae Gusev, 1953 (host: Lota lota), Gyrodactylus lucii Kulakovskaya, 1952 (host: Esox lucius), and Gyrodactylus spathulatus Mueller, 1936 (hosts: Catostomus commersonii [North America]; Catostomus catostomus [eastern Asia]; see Leis et al., 2021).

\section{Arctic charr (Salvelinus alpinus) are a competent host for several Gyrodactylus spp., including G. salaris}

Gyrodactylus infections of Arctic charr (S. alpinus) have been reported for several species, including Gyrodactylus birmani, G. derjavini, G. salmonis (under synonym: G. salvelini), and G. salaris (Harris et al. 2004; Kuusela et al. 2008). In Norway, the Arctic charr has been infected by several strains of $G$. salaris separated through cox 1 barcoding, indicating the species is not only susceptible to monogenean infections, but also tolerant as the infections were not reported as pathogenic. The mitochondrial strain $\operatorname{cox} 1^{\mathrm{F}}$ of $G$. salaris has spread through rainbow trout farming (Hansen et al., 2003) and been found on Arctic charr in Buskerud County, Norway (Robertsen et al., 2007; Olstad et al., 2007). Strain $\operatorname{cox} 1^{\mathrm{A}}$ represents the clone that caused the main Norwegian epidemic documented from G. salaris infecting $S$. salar and was also found on Arctic charr in Fustvatnet, Norway. In Skibotnelva, Norway, strain $\operatorname{cox} 1^{\mathrm{B}}$ of G. salaris infecting $S$. salar was treated twice with rotenone, but afterwards the parasite was still present on upstreamdwelling S. alpinus (Winger et al., 2008, 2012). These examples illustrate that Arctic charr appear to be a host quite tolerant of subclinical infections by several Gyrodactylus species, supporting the plausibility this host was involved in the circumpolar distribution of G. salmonis.

\section{Rainbow trout have not introduced $G$. salmonis outside of North America}

A natural host of G. salmonis is O. mykiss, a North American species that is one of the most widely introduced salmonids and commercially farmed fish worldwide (Fausch 2007). However, it is interesting that the only case of $G$. salmonis identified outside of boreal North America was reported from a feral trout population in Mexico (Rubio-Godoy et al., 2012). The cox 1 haplotype identified from Mexico was previously unique but found in this study from facilities located in Washington and Montana, U.S.A. (Fig. 2; RubioGodoy et al., 2012). A very plausible explanation for the lack of transmission of $G$. salmonis outside of North America involves the likelihood that only fertilized eggs were transported to other continents, thereby leaving their parasites behind.

\section{In exile, rainbow trout have adopted numerous salmonid parasites}

On new continents, $O$. mykiss has apparently lost its native parasite, G. salmonis, and became infected with a wide range of new parasites. The most commonly found parasites on rainbow trout, within the species or lineages studied in European farms, belong to G. salaris sensu lato. However, the most pathogenic Baltic salmon specific clade G. salaris sensu stricto has not been observed on rainbow trout, and the parasite strains spreading on $O$. mykiss have seldom infected S. salar (Kuusela et al., 2007). On rainbow trout, G. salaris is represented by several lineages identified with the $\operatorname{cox} 1$ gene, including the Ossetian strain in Lake Ladoga (Ieshko et al., 2015), the Norwegian $\operatorname{cox} 1^{\mathrm{F}}$ mentioned above (Hansen et al., 2003), and 
additional strains in Italy (Paladini et al., 2009). The hybrid $G$. pomeraniae $\times G$. lavareti was found in $O$. mykiss farms and has not been identified from wild populations (Kuusela et al., 2008). Furthermore, the following species presented in Figure 5 are molecularly identified strains collected from $O$. mykiss: $G$. taimeni (Vietnam), G. magnus (type host ITS in Vladivostok, ITS and $\operatorname{cox} 1$ in a Vietnam farm, ITS in China), G. truttae (Rokicka et al., 2007; Hahn et al., 2015), G. derjavini and G. derjavinoides (Malmberg et al., 2007), G. teuchis (Rokicka et al., 2007; Hahn et al., 2011, 2015; Ieshko et al., 2015), and the "alien" $G$. salaris (Lindenstrøm et al., 2003; Rokicka et al., 2007; Ziętara et al., 2010).

\section{The wageneri species group: Host switching capacity as an evolutionary novelty}

In an early molecular study of the wageneri group species, it was concluded that host switching was common in the evolution of Gyrodactylus (Ziętara and Lumme, 2002). However, in the freshwater-restricted subgenera G. (Gyrodactylus), all European species are parasites of cyprinids. In the subgenus $\mathrm{G}$. ( $\mathrm{Lim}$ nonephrotus), only the wageneri group parasitizes diverse host families, suggesting this group is more capable of host switching; other clades are much more conservative and primarily infect cyprinids. Due to low sampling coverage, these generalizations are weakly supported, but future surveys identifying Gyrodactylus from various fish families to test this hypothesis would be straightforward.

The results of this study are an incomplete outline describing an intriguing case of evolution within the framework of host-parasite interactions. The difficulties associated with the interpretation and unavoidable incompleteness resulting from the circumpolar scale should only encourage researchers as the most pronounced effects resulting from climatic change are expected to occur within this northern region inhabited by Coregonus, Oncorhynchus, Salvelinus, and Gyrodactylus.

\section{ACKNOWLEDGMENTS}

We would like to thank Dr. Perttu Koski, Dr. Paul Hershberger, and Dr. Marcia House for creating contacts among the widely scattered authors. We would also like to thank Dr. David Cone for assistance related to the specimens of Gyrodactylus salmonis collected from the Nanaimo River Hatchery as well as comments on the manuscript. We used the ITS of G. magnus (from type host Thymallus arcticus) that was collected and identified by Dr. Alexey Ermolenko in Vladivostok. Dr. Marek Ziętara produced and managed many of the DNA sequences. The study was supported by the Finnish Academy (grants 63787 and 134592 to JL). We would like to thank John Fisher (National Conservation Training Center, U.S. Fish and Wildlife Service) for locating reference materials. The findings and conclusions in this article are those of the authors and do not necessarily represent the views of the USFWS. Any use of trade, firm, or product names is for descriptive purposes only and does not imply endorsement by the USFWS or U.S. Government.

\section{LITERATURE CITED}

Bakke, T. A., Cable, J., and P. Harris. 2007. The biology of gyrodactylid monogeneans: the "Russian-doll killers." Advances in Parasitology 64:161-460.

Birky, C. W., and T. G. Barraclough. 2009. Asexual speciation. Pages 201-216 in I. Schön, K. Martens, K. and P. van Dijk, eds. Lost Sex. The Evolutionary Biology of Parthenogenesis. Springer, New York, New York. $615 \mathrm{pp}$.

Collins, C. M., and C. O. Cunningham. 2000. Characterization of the Gyrodactylus salaris Malmberg, 1957 (Platyhelminthes: Monogenea) ribosomal intergenic spaced (IGS) DNA. Parasitology 121:555-563.

Cone, D. K., M. Beverly-Burton, M. Wiles, and T. E. MacDonald. 1983. The taxonomy of Gyrodactylus (Monogenea) parasitizing certain salmonid fishes of North America, with a description of Gyrodactylus nerkae n. sp. Canadian Journal of Zoology 61:2587-2597.

Cone, D. K., and R. Cusack. 1988. A study of Gyrodactylus colemanensis Mizelle and Kritsky, 1967 and Gyrodactylus salmonis (Yin and Sproston, 1948) (Monogenea) parasitizing captive salmonids in Nova Scotia. Canadian Journal of Zoology 66:409-415.

Cone, D. K., and A. O. Dechtiar. 1986. On Gyrodactylus katharineri Malmberg, 1964, G. lotae Gussev, 1953 and G. lucii Kulakovskaya, 1952 from host fishes in North America. Canadian Journal of Zoology 64: 637-639.

Cunningham, C. O. 1997. Species variation within the internal transcribed spacer (ITS) region of Gyrodactylus (Monogenea: Gyrodactylidae) ribosomal RNA genes. Journal of Parasitology 86:215-219.

Cunningham, C. O., D. M. McGillivray, and K. MacKenzie. 1995. Phylogenetic analysis of Gyrodactylus salaris Malmberg, 1957 based on the small subunit (18S) ribosomal RNA gene. Molecular and Biochemical Parasitology 71:139-142.

Cusack, R., and D. K. Cone. 1986. Gyrodactylus salmonis (Yin and Sproston, 1948) parasitizing fry of Salvelinus fontinalis (Mitchill). Journal of Wildlife Diseases 22:209-213.

Esin, E. V., and G. N. Markevich. 2018. Evolution of the Charrs, genus Salvelinus (Salmonidae). 1. Origins and expansion of the species. Journal of Ichthyology 58: 187-203.

Fausch, K. 2007. Introduction, establishment and effects of non-native salmonids: considering the risk of rainbow trout invasion in the United Kingdom. Journal of Fish Biology 71:1-32. 
Fromm, B., Burow, S., Hahn, C., and L. Bachmann. 2014. MicroRNA loci support conspecificity of Gyrodactylus salaris and Gyrodactylus thymalli (Platyhelminthes: Monogenea). International Journal of Parasitology 44:787-793.

Gilmore, S. R., C. L. Abbott, and D. K. Cone. 2010. The placement of Gyrodactylus salmonis (Yin \& Sproston) in the molecular phylogeny of studied members of the $G y$ rodactylus wageneri-group parasitizing salmonids. Journal of Fish Diseases 33:461-467.

Gilmore, S. R., D. K. Cone, G. Lowe, S. K. King, S. R. M. Jones, and C. L. Abbott. 2012. Molecular phylogeny of Gyrodactylus (Monogenea) parasitizing fishes in fresh water, estuarine, and marine habitats in Canada. Canadian Journal of Zoology 90:776-786.

Hahn, C., T. A. Bakke, L. Bachmann, S. Weiss, and P. D. Harris. 2011. Morphometric and molecular characterization of Gyrodactylis teuchis Lautraite, Blanck, Thiery, Danie \& Vigneuille, 1999 (Monogenea: Gyrodactylidae) from an Austrian brown trout population. Parasitology International 60:480-487.

Hahn, C., S. J. Weiss, S. Stojanowski, and L. Bachmann. 2015. Co-speciation of the ectoparasite Gyrodactylus teuchis (Monogenea, Platyhelminthes) and its salmonid hosts. PloS ONE 10:e127340

Hansen, H., L. Bachmann, and T. A. Bakke. 2003. Mitochondrial DNA variation of Gyrodactylus spp. (Monogenea, Gyrodactylidae) populations infecting Atlantic salmon, grayling, and rainbow trout in Norway and Sweden. International Journal for Parasitology 33: 1471-1478.

Hansen, H., T. A. Bakke, and L. Bachmann. 2007. Mitochondrial haplotype diversity of Gyrodactylus thymalli (Paltyhelminthes, Monogenea): extended geographic sampling in United Kingdom, Poland and Norway reveals further lineages. Parasitology Research 100: 1389-1394.

Hansen, H., A. Jørgensen, and T. Mo. 2012. Spin-off from routine parasite diagnostics of Atlantic salmon; first report of Gyrodactylus alexanderi in Norway. Bulletin of the European Association of Fish Pathologists 32:14-18.

Harris, P. D., A. P. Shinn, J. Cable, and T. A. Bakke. 2004. Nominal species of the genus Gyrodactylus von Nordmann 1832 (Monogenea: Gyrodactylidae), with a list of principal host species. Systematic Parasitology 59:1-27.

Ieshko, E., D. Lebedeva, and J. Lumme. 2015. A new Gyrodactylus strain on brown trout (Salmo trutta) in Jänisjärvi, Russian Karelia, and a literature revision of salmonid parasites of the genus Gyrodactylus in North Western Russia and adjacent areas. Acta Parasitologica 60:75-84.

Johnsen, B. O., and A. J. Jensen. 1991. The Gyrodactylus story in Norway. Aquaculture 98:289-302.

Koskinen, M. T., I. Knizhin, C. R. Primmer, C. Schlötterer, and S. Weiss. 2002. Mitochondrial and nuclear DNA phylogeography of Thymallus spp. (grayling) provides evidence of ice-age mediated environmental perturbations in the world's oldest body of fresh water, Lake Baikal. Molecular Ecology 11:2599-2611.

Kumar, S., G. Stecher, M. Li, C. Knyaz, and K. Tamura. 2018. MEGA X: Molecular Evolutionary Genetics Analysis across computing platforms. Molecular Biology and Evolution 35:1547-1549.
Kumar, S., G. Stecher, and K. Tamura. 2016. MEGA7: Molecular Evolutionary Genetics Analysis version 7.9 for bigger datasets. Molecular Biology and Evolution 33:1870-1874.

Kuusela, J., M. S. Ziętara, and J. Lumme. 2007. Hybrid origin of Baltic salmon-specific parasite Gyrodactylus salaris: a model for speciation by host switch for hemiclonal organisms. Molecular Ecology 16:5234-5245.

Kuusela, J., M. S. Ziętara, and J. Lumme. 2008. Description of three new European cryptic species of Gyrodactylus Nordmann, 1832 supported by nuclear and mitochondrial phylogenetic characterization. Acta Parasitologica 53:120-126.

Leis, E., R. Easy, and D. Cone. 2021. A variant of Gyrodactylus mediotorus King, Marcogliese, Forest, McLaughlin and Bentzen, 2013 (Monogenea) identified from weed shiner (Notropis texanus) in Wisconsin portions of the upper Mississippi River. Systematic Parasitology 98:247-253.

Leis, E., S. King, S. Leis, and D. Cone. 2016. Infections of Gyrodactylus crysoleucas and Gyrodactylus sp. (Monogenea) at a Golden shiner (Notemigonus crysoleucas) farm in Minnesota. Comparative Parasitology 83: 106-110.

Lindenstrøm, T., C. M. Collins, J. Bresciani, C. O. Cunningham, and K. Buchmann. 2003. Characterization of a Gyrodactylus salaris variant: infection biology, morphology and molecular genetics. Parasitology 127 : 165-177.

Lõugas, L., P. Wojtal, J. Wilczyński, and K. Stefaniak. 2013. Paleolithic fish from Southern Poland: a paleozoogeographical approach. Archaeofauna 22:123-131.

Lumme, J., P. Anttila, P. Rintamäki, P. Koski, and A. Romakkaniemi. 2016. Genetic gradient of a hostparasite pair persisted ten years against physical mobility: Baltic Salmo salar vs. Gyrodactylus salaris. Infection, Genetics and Evolution 45:33-39.

Lumme, J., H. Mäkinen, A. V. Ermolenko, J. L. Gregg, and M. S. Ziętara. 2016. Displaced phylogeographic signals from Gyrodactylus arcuatus, a parasite of the three-spined stickleback Gasterosteus aculeatus, suggest freshwater glacial refugia in Europe. International Journal for Parasitology 46:545-554.

Lumme, J., M. Y. Ozerov, A. E. Veselov, and C. R. Primmer. 2015. The formation of landlocked populations of Atlantic salmon. Chapter 2 in T. Vladic and E. Petersson, eds. Evolutionary Biology of Atlantic Salmon. CRC Press, Boca Raton, Florida. 26-43.

Lumme, J., M. S. Ziętara, and D. Lebedeva. 2017. Ancient and modern genome shuffling: reticulate mitonuclear phylogeny of four related allopatric species of $G y$ rodactylus von Nordmann, 1832 (Monogenea: Gyrodactylidae), ectoparasites of the Eurasian minnow Phoxinus phoxinus (L.) (Cyprinidae). Systematic Parasitology 94:183-200.

Magnan, P., C. Audet H. Glémet, M. Legault M. A. Rodriguez, and E. B. Taulor. 2002. Ecology, behaviour and conservation of the charrs, genus Salvelinus. Environmental Biology of Fishes 64:9-14.

Malmberg, G. 1970. The excretory systems and the marginal hooks as a basis for the systematics of Gyrodactylus (Trematoda, Monogenea). Arkiv for Zoologi 23:1-235.

Malmberg, G., C. M. Collins, C. O. Cunningham, and B. J. Jalali. 2007. Gyrodactylus derjavinoides sp. nov. 
(Monogenea, Platyhelminthes) on Salmo trutta trutta L. and G. derjavini Mikailov, 1975 on S. t. caspius Kessler, two different species of Gyrodactylus - combined morphological and molecular investigations. Acta Parasitologica 52:89-103.

Mangerud, J., V. Astakhov, and J. I. Svendsen. 2002. The extent of the Barents-Kara ice sheet during the Last Glacial Maximum. Quaternary Science Reviews 21:111-119.

Matějusová, I., M. Gelnar, A. J. McBeath, C. M. Collins, and C. O. Cunningham. 2001. Molecular markers for gyrodactylids (Gyrodactylidae: Monogenea) from five fish families (Teleostei). International Journal for Parasitology 31:738-745.

Meinilä, M., J. Kuusela, M. Ziẹtara, and J. Lumme. 2002. Primers for amplifying $\sim 820$ bp of highly polymorphic mitochondrial COI gene of Gyrodactylus salaris. Hereditas 137:72-74.

Mo, T. A. 1991. Seasonal variations of opisthaptoral hard parts of Gyrodactylus salaris Malmberg, 1957 (Monogenea: Gyrodactylidae) on parr of Atlantic salmon Salmo salar L. in the River Batnfjordselva, Norway. Systematic Parasitology 19:231-240.

Mo, T. A. 1993. Seasonal variations of the opisthaptoral hard parts of Gyrodactylus derjavini Mikailov, 1975 (Monogenea: Gyrodactylidae) on brown trout Salmo trutta L. parr and Atlantic salmon S. salar L. parr in the River Sandvikselva, Norway. Systematic Parasitology 26:225-231.

Mueller, J. F. 1936. Studies on North American Gyrodactyloidea. Transactions of the American Microscopical Society 55:55-72.

Olstad, K., G. Robertsen, L. Bachmann, and T. A. Bakke. 2007. Variation in host preference within Gyrodactylus salaris (Monogenea): an experimental approach. Parasitology 134:589-597.

Ondračková, M., M. Seifertová, A. Bryjová, E. Leis, and P. Jurajda. 2020. Morphometric and genetic evidence for cryptic diversity in Gyrodactylus (Monogenea) infecting non-native European populations of Ameiurus nebulosus and A. melas. Parasitology 147: $1700-1711$.

Paladini, G., A. Gustinelli, M. L. Fioravanti, H. Hansen, and A. P. Shinn. 2009. The first report of Gyrodactylus salaris Malmberg, 1957 (Platyhelminthes, Monogenea) on Italian cultured stocks of rainbow trout $(\mathrm{On}$ corhynchus mykiss Walbaum). Veterinary Parasitology 165:290-297.

Power, G. 2002. Charrs, glaciations and seasonal ice. Environmental Biology of Fishes 64:17-35.

Reshetnikov, Y.S. 2003. Atlas of Russian Freshwater Fishes. Vol. 1. Nauka, Moscow. 378 pp.

Reyda, F. B., S. M. Wells, A. V. Ermolenko, M. S. Ziętara, and J. Lumme. 2019. Global parasite trafficking: Asian Gyrodactylus (Monogenea) arrived to the U.S.A. via invasive fish Misgurnus anguillicaudatus as a threat to amphibians. Biological Invasions 22:391-402.

Robertsen, G., H. Hansen, L. Bachmann, and T. A. Bakke. 2007. Arctic charr (Salvelinus alpinus) is a suitable host for Gyrodactylus salaris (Monogenea, Gyrodactylidae) in Norway. Parasitology 134:257-267.

Rokicka, M., J. Lumme, and M. S. Ziętara. 2007. Identification of Gyrodactylus ectoparasites in Polish salmonid farms by PCR-RFLP of the nuclear ITS segment of ri- bosomal DNA (Monogenea, Gyrodactylidae). Acta Parasitologica 52:185-195.

Rubio-Godoy, M., G. Paladini, M. A. Freeman, A. GarciaVasquez, and A. P. Shinn. 2012. Morphological and molecular characterisation of Gyrodactylus salmonis (Platyhelminthes, Monogenea) isolates collected in Mexico from rainbow trout (Oncorhynchus mykiss Walbaum). Veterinary Parasitology 186:289-300.

Sokolov, G. S., and I. I. Gordeev. 2014. The first record of Monogenea (Plathelminthes) parasitic on char (Salmonidae: Salvelinus) from Kronotsky Lake (Kamchatka Peninsula), Russia. Invertebrate Zoology 11:353-369.

Vanhove, M. P. M., B. Tessens, C. Schoelink, U. Jondelius, D. T. J. Littlewood, T. Artois, and T. Huyse. 2013. Problematic barcoding in flatworms: a case-study on monogeneans and rhabdocoles (Platyhelminthes). ZooKeys 365:355-379.

Winger, A. C., M. Kanck, R. Kristoffersen, and R. Knudsen. 2008. Seasonal dynamics and persistence of $G y$ rodactylus salaris in two riverine anadromous Arctic charr populations. Environmental Biology of Fishes 83: $117-123$.

Winger, A. C., R. Kristoffersson, and R. Knudsen. 2012. Rapid transmission of Gyrodactylus salaris (Malmberg, 1957) between live Arctic charr, Salvelinus alpinus (L.), fry. Journal of Fish Diseases 35:781-784.

Yin, W. Y., and N. G. Sproston. 1948. Studies on the monogenetic trematodes of China: parts 1-5. Sinesia 19: $57-85$.

You, P., J. MacMillan, and D. Cone. 2011. Local patchiness of Gyrodactylus colemanensis and G. salmonis parasitizing salmonids in the South River watershed, Nova Scotia, Canada. Diseases of Aquatic Organisms 96: 137-143.

Ziętara, M. S., A. Arndt, A. Geets, B. Hellemans, and F. A. M. Volckaert. 2000. The nuclear rDNA region of Gyrodactylus arcuatus and G. branchicus (Monogenea: Gyrodactylidae). Journal of Parasitology 86:368-1373.

Zietara M. S., J. Kuusela, and J. Lumme. 2006. Escape from an evolutionary dead-end: a triploid clone of $G y$ rodactylus salaris is able to revert to sex and switch host (Platyhelminthes, Monogenea, Gyrodactylidae). Hereditas 143:86-92.

Ziętara, M. S., J. Kuusela, A. Veselov, and J. Lumme. 2008. Molecular faunistics of accidental infections of Gyrodactylus Nordmann, 1832 (Monogenea) parasitic on salmon Salmo salar L. and brown trout Salmo trutta L. in NW Russia. Systematic Parasitology 69:123-135.

Ziettara, M. S., D. Lebedeva, G. Muñoz and J. Lumme. 2012. A monogenean fish parasite, Gyrodactylus chileani $\mathrm{n}$. sp., belonging to a novel marine species lineage found in the South-Eastern Pacific and the Mediterranean and North Seas. Systematic Parasitology 83: 159-167.

Ziętara, M. S., and J. Lumme. 2002. Speciation by host switch and adaptive radiation in a fish parasite genus Gyrodactylus (Monogenea: Gyrodactylidae). Evolution 56:2445-2458.

Zietara, M. S., and J. Lumme. 2003. The crossroads of molecular, typological and biological species concepts: two new species of Gyrodactylus Nordmann, 1832 (Monogenea, Gyrodactylidae). Systematic Parasitology 55:39-52. 
Ziętara, M. S., and J. Lumme. 2004. Comparison of molecular phylogeny and morphological systematics in fish parasite genus Gyrodactylus Nordmann, 1832 (Monogenea, Gyrodactylidae). Zoologica Poloniae 49: 5-28.
Ziętara, M. S., M. Rokicka, S. Stojanovski, and J. Lumme. 2010. Introgression of distant mitochondria into the genome of Gyrodactylus salaris: nuclear and mitochondrial markers are necessary to identify parasite strains. Acta Parasitologica 55:20-28. 